\title{
Why Does Trust Mediate the Effects of Ethical and Authentic Leadership in Korean Firms?
}

\author{
KISUK CHO* AND HYE YUN PARK ${ }^{* *}$
}

\begin{abstract}
Walumbwa et al. (2008) conducted research into the positive and direct effects of ethical and authentic leadership on organizational outcomes using a student sample in the United States. However, the study hypothesizes that in a non-American context within Korean firms, no direct relationship exists between the two leadership styles and organizational outcomes. This is due to the unique culture of Korea where trust is based on private networks such as regional, school, and blood ties. The results show that both leadership styles are only effective when they are mediated by followers' trust. The results imply that the achievement of leadership requires more than the authenticity of the leader, rendering support for Eagly's (2005) suggestion that authenticity is a relational concept.
\end{abstract}

Keywords: Ethical Leadership, Authentic Leadership, Trust, Organizational Outcomes, Mediation Effect

* Professor, Ewha Womans University, Seoul, South Korea;

E-mail: choks@ewha.ac.kr

** Invited Professor, Ewha Womans University, Seoul, South Korea;

E-mail: hypark001@ewha.ac.kr

DOI: 10.16934/isr.16.2.201512.49 


\section{INTRODUCTION}

Recent cases of corporate fraud and other such scandals have heightened interest in value-based leadership, which emphasizes leaders' ethics and their positive effects on employees. Yet, much remains unexplained with regard to its theoretical construct and empirical effects. Walumbwa et al.'s (2008) pioneering study on authentic leadership illuminates the conceptual distinctions amongst different value-based leadership styles, namely ethical and authentic leadership. The authors investigate the psychometric properties of authentic leadership, demonstrating not only the close association between the ethical and authentic leadership constructs, but also their mutual distinctiveness. Ethical leadership promotes followers' ethical conduct, whereas authentic leadership focuses on leaders' authenticity, which is expected to foster followers' positive self-development. Authenticity can be exhibited as the leaders "align their actions and behaviors with their core internalized values and beliefs" (Harvey et al. 2006, 1).

The present study attempts to further develop Walumbwa et al.'s model by proposing trust as a mediating variable between leadership and organizational outcomes. Trust has long been considered to be a pivotal factor influencing leadership effectiveness, yet how it functions with ethical and authentic leadership constructs is rarely addressed in the literature. Although a host of studies demonstrate a significant association between followers' trust in leaders and their positive perception of the leaders' ethical or authentic qualities (e.g., Dirks and Ferrin 2002; Akker et al. 2009; Ponnu et al. 2009), only a few studies treat trust as a mediator between these leadership styles and organizational outcomes. This is surprising as a number of studies on ethical or authentic leaders found mediation effects through various motivational mechanisms such as empowerment and identification (Walumbwa et al. 2010); self-esteem (Avey et al. 2010); and job satisfaction and affective commitment (Ruiz-Palomino et al. 2011), to name a few.

The focus will be placed upon trust-building processes in Korea, which diverge from those in Western societies. Confucian philosophy is deeply embedded in many aspects of social and organizational life in Korea as it is in other East Asian countries. Confucianism is known to place great emphasis on ethics and authenticity in leadership (Zang et al. 2012), and in fact, leadership with ethical quality is not a new concept in Korea (H.S. Kim and Chung 2008; Shin 2012; Shin et al. 2014). However, the effects of leadership in Asian culture, which are often based upon interpersonal relationships, remain largely unexplored. We hypothesize that interpersonal trust based on private networks such as schools, blood, and regional ties in Korean firms, may prevent followers from perceiving leaders' true ethics or authenticity. Therefore, ethical and authentic leadership can only be effective in influencing organizational outcomes when they are mediated by trust in the Korean context. 
Korea is selected as a case because the country has successfully achieved modernization and industrialization in a short period of time. Many Korean firms are rapidly becoming global, but their organizational culture still remains at best traditional or complex (Cho et al. 2014). Korean companies typically prioritize competence and efficiency over ethics in order to achieve rapid industrialization. Consumer groups have only recently started to protest against the corrupt and unethical accounting practices of large conglomerates. In response, firms have launched training and awareness programs for ethical management. If we are successful in finding a positive effect of authentic and ethical leadership in Korean companies, then this will offer corporations more incentive to set a good example, which firms in neighboring countries, sharing similar cultures, could quickly follow.

Theoretically, the present study contributes to leadership literature in two major ways: First, it extends Walumbwa et al.'s (2008) model by incorporating trust as a mediating variable in a culture where trust building processes differ from those of Western culture. Second, the study also facilitates the applicability of existing theories to a non-US context, testing the cross-cultural validity of the two leadership measures. Most previous studies on ethical and authentic leaderships have been conducted within the US, thus Bass (1990) and Walumbwa et al. (2008) among others have called for research to be undertaken in more diverse settings. We discovered that some of the questionnaires measuring ethical and authentic leadership do not fit within the Korean context due to differences in culturally desirable behaviors.

In Figure 1, the research model of the study is presented. The previous literature and the development of our hypothesis will be discussed in the next section.

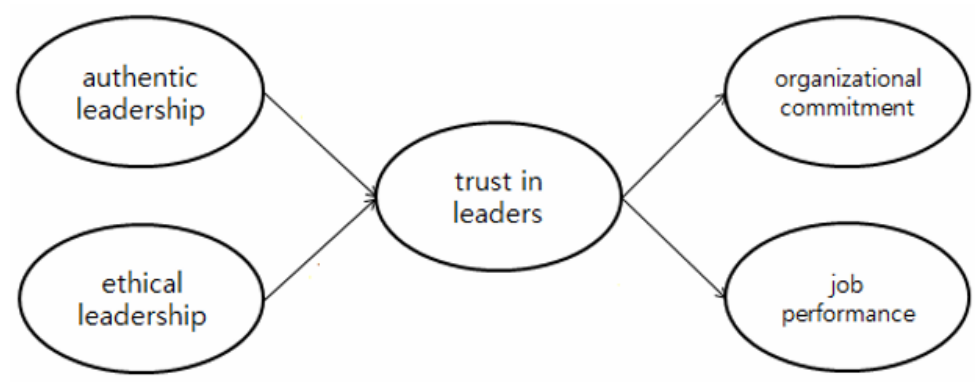

Figure 1. CONCEPTUAL MOdEL OF THE STUdy

\section{THEORY AND HYPOTHESES}

\section{Ethical and Authentic leadership}

Ethical leadership can be defined as "the demonstration of normatively appropriate conduct through personal actions and interpersonal relationships, and 
the promotion of such conduct to followers through two-way communication, reinforcement, and decision-making" (Brown et al. 2005, 120). Leaders behave ethically "when they are doing what is morally right, just, and good, and when they help to elevate followers' moral awareness and moral self-actualization" (Zhu et al. 2004, 16). To be perceived as being ethical, leaders are supposed to exhibit a higher moral standard and act consistently to their beliefs and ethical values. Ethical leadership has been known to have two sub-dimensions: moral persons and moral managers (Trevino et al. 2000). The first sub-dimension refers to the personal aspect of ethical leaders in terms of their core values and conduct. The second one is related to the organizational aspect of ethical leadership. Akker et al. (2009) pointed out that being a moral person is a crucial prerequisite for a moral manager.

Thus far, the theoretical conceptualization of ethical leadership has been well defined by a series of leadership and organizational studies (e.g., Enderle 1982; Zhu et al. 2004; Brown et al. 2005; Brown and Trevino 2006; Palanski and Yammarino 2007; Mayer et al. 2009, 2012). These studies have demonstrated how ethical aspects of leaders are perceived by followers, and how leaders wield influence within organizations, either by introducing carrot-and-stick measures to reinforce ethical conduct or by creating a culture of ethics. For example, Brown, Trevino and Harrison (2005) emphasize the transactional characteristics of ethical management in which leaders employ incentives as well as punishments to motivate their followers' ethical behavior. Mayer et al. (2009) demonstrated that ethical leadership possesses particular role modelling or cascading effects on employees' ethical behavior.

Similar to ethical leadership, authentic leadership is also known to emphasize ethical values and conduct (e.g., May et al. 2003) within organizations, therefore is often categorized as a type of value-based leadership (Gronn 2001). Scholarly attention to authentic leadership emerged around the 1970s (Clapp-Smith et al. 2009), but theoretical development of the concept and particularly the examination of its effects on work outcomes is largely a recent phenomenon. Authentic leaders are "persons who have achieved high levels of authenticity in that they know who they are, what they believe and value, and they act upon those values and beliefs while transparently interacting with others" (Avolio et al. 2004, 802). Authentic leaders obtain moral influence over employees through their normatively appropriate behaviors.

In the previous literature, ethical and authentic leadership are often mentioned together, implying the close relationship between two. Yet, before Walumbwa et al. (2008), there was no theoretical attempt to explicate how the two are associated. After extensive reviews of previous literature and a series of tests, Walumbwa et al. (2008) verified the four dimensions of the authentic leadership construct - selfawareness, relational transparency, balanced processing of information, and internalized moral perspective. Furthermore, they found that the two core dimensions 
of ethical leadership-moral persons and moral manager-and one dimension of authentic leadership-internalized moral perspective-are shared by each other. Therefore, we suggest a hypothesis as follows:

\section{Hypothesis 1: Ethical leadership and authentic leadership are positively related to each other.}

\section{Ethical/Authentic Leadership and Trust}

Trust has drawn much attention in leadership literature (Bass 1990) for its influence on organizational effectiveness. Burk et al. (2007) pointed out that trust can be conceptualized in the following three ways: a personal trait of propensity to trust (Rotter 1967); the follower's cognitive, motivational, and affective states that can lead to certain outcomes; and a process through which other behaviors and attitudes are either strengthened or weakened. Of the three traits, the present study focuses on the second. Trust can create a psychological condition by which followers willingly accept leaders' authority and tasks required to be undertaken for the leader, as trust is founded upon a belief that the other party's behavior is predictable and trustworthy (Caldwell et al. 2008). If the leaders exhibit high moral standards and integrity, this would provide the followers with an even firmer ground for placing their beliefs in these leaders.

Thus far, some empirical and theoretical studies have shown that followers' trust in their leaders tends to have a positive relationship with their perception of the leader's ethical and/or authentic qualities. For example, Akker et al. (2009) showed all multifaceted ethical aspects of leadership positively affect followers' trust in their leaders. Ponnu et al. (2009) in their study on Malaysian firms demonstrated that ethical leadership is associated with both organizational commitment and trust in leaders. Avolio et al. (2004) argue that the followers can place higher trust in authentic leaders whose reputation is built upon their moral standards, integrity, and honesty. Gardner et al. (2005) also point out that those who perceive their leaders' authenticity highly trust these leaders, while tending to develop their own authenticity. Thus, with the evidence aforementioned, we suggest the following hypothesis:

Hypothesis 2: Ethical leadership is positively related to trust in leaders.

Hypothesis 3: Authentic leadership is positively related to trust in leaders.

\section{Trust and Organizational Outcomes}

Organizational outcomes that are positively associated with trust in leaders would include both attitudinal and behavioral responses from the followers. The former includes increased job satisfaction and organizational commitment (Pillai 
et al. 1999) while the latter refers to improved job performances (Dirks 2000; Dirks and Ferrin 2002). Furthermore, extra-role behaviors such as organizational citizenship behaviors (OCB) are also known to be induced by trust in leaders (Podsakoff et al. 1990; Pillai et al. 1999). In the present study, we intended to investigate how trust leads to both attitudinal and behavioral results in these leadership styles. Therefore, we selected organizational commitment as an attitudinal outcome and job performance as a behavioral outcome.

Organizational commitment can be defined as "the relative strength of an individual's identification with and involvement in a particular organization" (Mowday et al. 1979, 226). Pillai et al. (1999) pointed out that trust in leaders and commitment to organizations are both necessary conditions for maintaining and growing successful organizations, yet trust can predict one's level of commitment. In regard to job performance, Dirks and Ferrin (2002) demonstrated that the association between trust and attitudinal outcomes is much stronger than that between trust and performance, but a significant relationship exists in both cases. Moreover, they discovered that job performances are more strongly associated with trust in direct reports than trust in organizational leadership, implying that for improvement in performances, trusting relationship with direct leaders is much more important than that with top leaders.

From the results of the previous research, we derive the following hypothesis:

\section{Hypothesis 4: Trust in leaders is positively related to organizational commitment and job performance.}

\section{Trust as a Mediator}

Hypothesizing and constructing the mediation effects of trust between ethical/ authentic leadership and outcomes has been attempted in several studies. Avolio et al. (2004) constructed a conceptual framework which delineated a path from authentic leadership to followers' work attitudes (e.g., commitment, job satisfaction, meaningfulness, and engagement) and behaviors (e.g., job performance, extra effort, withdrawal behavior) through the intermediary variables such as personal/social identification, hope, trust, positive emotions, and optimism. Brown, Trevino and Harrison (2005) suggested that when employees are treated well and fairly by their trusted leaders, who portray ethical traits, they are likely to reciprocate by being more dedicated to work. Based on the social exchange theory, Avolio and Gardner (2005) proposed a model illustrating how authentic leadership influences followers' attitudes and behaviors mediated by positive emotions and trust. The authors argue that authentic leaders' high ethical standards can foster positive expectations among followers, facilitating their trust in and willingness to cooperate with the leader for the benefit of the organization. 
However, empirical tests of the link between ethical/authentic leadership-trustoutcomes are still rare. So far, four empirical studies have explicated the mediation of trust between ethical and authentic leaderships with their outcomes. Wong et al. (2009) studied healthcare organizations in Canada, adopting Walumbwa et al.'s (2008) four-dimension authentic leadership construct and discovered partial evidence on the relationship between authentic leadership and outcome variables. ClappSmith et al. (2009) conducted a group-level study (26 retail stores in the US) on the relationship between authentic leadership and positive psychology capital, mediated by trust and found that authentic leadership has both a direct and an indirect effect on performance (i.e., growth in sales). The authors concluded that the perception of authentic leadership leads to trust in the leader, and in turn leads to better performance. Chungtai et al. (2014) found in their study of trainees for an accountant firm in Ireland that ethical leadership enhances employees' work engagement and wellbeing when mediated by trust in supervisors. Finally et al. (2014) in their study of a Chinese firm found a number of positive effects of ethical leadership on employees' voice behavior mediated by organizational identity, which in turn was moderated by one's organizational trust. The study demonstrates how one's positive perception of ethical leadership can motivate employees' contributions to organizations through a high level of organizational trust.

We argue that the examination of the mediation of trust between leaders and employees is particularly important in the study of leadership in a non-US context where some cultural effects need to be considered when analyzing the interaction between leaders and followers. Of the cultural traits found in the leader-follower interactions, Guanxi in China is drawing much attention from both academics and practitioners. Han et al. (2012) argued that trust between supervisors and followers is highly related to their Guanxi in the Chinese context. Similar concepts to Guanxi in Korea are Yongo, Yonjul, and Inmaek (Horak 2014). From the perspective of cross-cultural business and management studies, Horak (2014) observes three informal ties-region, school, and family ties-being pivotal in forming the relation-based culture in Korea and Korean firms. Yonjul has a more negative connotation than the other two and Inmaek is the most general description of the informal network but on occasions develops into the other two. Horak argues that without understanding the intricate nature of personal ties within Korean firms, their management practices can only be partially explained.

Communication and public relations research has also demonstrated that unique cultural beliefs and attitudes lead Koreans to a particular communication style used to build and maintain relationships. Yum and Canary (2003) identified four distinct features of cultural beliefs and attitudes in Korea toward interpersonal relationships and communication: Eui-ri, Cheong(精), Noon-chi, and Yon(然). Eui-ri refers to “one's attachment and loyalty to his or her important relational partner(s)" (281). Cheong refers to a feeling that can make an individual extend 
the meaning of "self" to include others and voluntarily engage in selfless behavior. This feeling is built on "a long history of interactions, mutual experiences, deeply rooted feelings, and mutual interdependence" (283). Noon-chi refers to a "tacit, high context communication tactic" that helps individuals to "read situational cues well and react promptly" (283) to save face and create a positive image of themselves. Finally, Yon refers to a belief that "relationships are formed, maintained, and terminated by uncontrollable external forces" (284) and thus any arbitrary efforts to build relationships without yon may be unfruitful. Berkowitz and Lee (2004) examined the role of Cheong in media relationships in Korea and suggested that it has considerable influence on the relationship between journalists and PR practitioners. Jo and Kim (2004) found that building and maintaining informal and personal relationships (e.g., Yon) with journalists are extremely important in media relationships in Korea and argued that Koreans tend to emphasize harmonious relationships, resulting in PR practitioners' reliance on personal networks for addressing negative publicity or organizational problems.

Given the uniqueness of interpersonal relationships in the Korean cultural context, we postulate that trust as a mediating factor between leadership and organizational outcomes will be even more critical in Korean firms. In Korean firms, followers will not consider the ethical and/or authentic leadership traits of their leaders as a motivator to change their attitudes and behaviors within organizations unless they build up enough trust with the leaders. In other words, we expect that ethical and authentic leadership may have no direct impact upon these outcomes unless they are mediated by trust.

Hypothesis 5: When ethical leadership is controlled for, authentic leadership is only indirectly related to organizational commitment and job performance mediated by trust.

Hypothesis 6: When authentic leadership is controlled for, ethical leadership is only indirectly related to organizational commitment and job performance mediated by trust.

\section{METHODOLOGY}

\section{Models}

We employed the structural equation modelling (SEM) technique, which combines a path analysis with a factor analysis. SEM is particularly useful when an analysis involves the measurement of latent variables and the simultaneous testing of multiple models. As shown in Figure 1, we test the mediating effect of trust in leaders. To see if there is any change when the direct effect is considered simultaneously, we test both direct and indirect effects in an alternative model. 


\section{Data}

For the empirical analysis, we obtained a sample of full-time employees from nine large firms, which had more than 200 employees in Korea during a period in May 2009. HR managers of these firms distributed and later gathered the questionnaires. The characteristics of the firms surveyed varied in terms of industry types: two manufacturing companies, one energy company, one telecommunications company, one pharmaceutical company, and two service industry companies. Another two companies were large Korean-style conglomerates involving multiple sectors. Before the main survey, we administered a pilot survey to test the reliability and validity of our questionnaire. Two firms were selected for this pilot survey, and some revisions were made to the original questionnaire based on the results. For the main survey, a total of 305 employees from the sampled firms were surveyed; of them, 193 employees responded (response rate was 63.3\%). The ranks of the respondents ranged from entry-level staff to mid-level managers.

Because the leadership and the outcome data were all collected using a single survey from the employees of the organizations, the results may be affected by the common method variance (CMV). To examine the potential effect of this bias, we conducted Harman's test (1967). The test dictates that if over 50\% of variability is explained by a single factor then the survey may be biased (Podsakoff et al. 2003). The result showed that no single factor was responsible for more than $50 \%$ of the variability in our data. Thus, CMV was not considered to be a problem in the given study.

The data was analyzed using two statistical packages: AMOS19 for confirmatory factor analysis as well as structural equation models and SPSS22 for the rest of the analysis. Table 1 shows the descriptive statistics. Among the 193 respondents, $64.2 \%$ were male; $58.1 \%$ were in their thirties; $56.5 \%$ were married; and more than $90 \%$ had a bachelor's degree or higher. Regarding organizational rank, $29.5 \%$ were general staff members; $12.1 \%$, assistant managers; $23.7 \%$, deputy managers; $17.9 \%$, managers; $10 \%$, deputy general managers; and $6.8 \%$, general managers. In regards to tenure, $29.3 \%$ had worked at least 10 years or more in the current organization; $27.1 \%$, from 3 to 7 years; and $22.9 \%$, from 6 months to 3 years.

\section{Measurement}

\section{(1) Ethical leadership}

To measure ethical leadership, we adopted the Ethical Leadership Scale (ELS) (Brown, Trevino and Harrison 2005). The ELS has 10 items, including the sample item "My boss conducts his/her personal life in an ethical manner." For the 
TABLE 1. DESCRIPTIVE STATISTICS

\begin{tabular}{llr}
\hline \multicolumn{1}{c}{ Variable } & \multicolumn{1}{c}{ Description } & $\mathrm{N}(\%)$ \\
\hline \multirow{2}{*}{ Sex } & Male & $122(64.2 \%)$ \\
& Female & $68(35.8 \%)$ \\
\hline \multirow{3}{*}{ Age } & $19-29$ & $42(22.0 \%)$ \\
& $30-39$ & $110(58.1 \%)$ \\
& $40-49$ & $32(16.8 \%)$ \\
Marital status & $50-59$ & $6(3.1 \%)$ \\
\hline \multirow{4}{*}{ Education } & Single & $83(43.5 \%)$ \\
& Married & $107(56.0 \%)$ \\
& Widowed/divorced & $1(0.5 \%)$ \\
\hline \multirow{4}{*}{ Rank } & High school diploma & $7(3.7 \%)$ \\
& Bachelor's degree & $153(80.5 \%)$ \\
& Master's degree & $28(14.7 \%)$ \\
& Ph.D & $2(1.1 \%)$ \\
\hline Staff & $56(29.5 \%)$ \\
& Assistant manager & $23(12.1 \%)$ \\
& Deputy manager & $45(23.7 \%)$ \\
& Manager & $34(17.9 \%)$ \\
Tenure & Deputy general manager & $19(10.0 \%)$ \\
& General manager & $13(6.8 \%)$ \\
\hline & Less than 6 months & $14(7.4 \%)$ \\
& 6 months to less than 3 years & $43(22.9 \%)$ \\
& 3 years to less than 7 years & $52(27.1 \%)$ \\
& 7 years to less than 10 years & $24(13.3 \%)$ \\
& 10 years or more & $57(29.3 \%)$ \\
\hline
\end{tabular}

present analysis, the Korean version of the ELS which is translated by H.S. Kim and Chung (2008) was adopted. As we conducted explorative factor analysis, the fourth item, which states "my boss disciplines employees who violate ethical standards," showed the lowest factor loading (.49). We suspect there may be a contextual effect for this. Of various cultural traits of informal relationships embedded in Korean society, Cheong (精) (Yum and Canary 2003; Berkowitz and Lee 2004) may have a particular relevance in this case. Cheong may sometimes prevent leaders from taking disciplinary action against followers who form personal ties with them within organizations, because one of its principal tenets is "who you know is more important than who you are." However, this attitude can be a major barrier in achieving fairness, which is considered to be an important element of ethical leadership. Thus, we eliminated the fourth item and constructed alternative ELS by excluding the fourth item. The internal reliability (Cronbach's alpha) of this new ethical leadership measure was .95 .

\section{(2) Authentic Leadership}

Authentic leadership is measured by the Authentic Leadership Questionnaire (ALQ) (Gardner, Avolio and Walumbwa 2006; Walumbwa et al. 2008). The ques- 
tionnaire included 16 items, which in turn fall into the four categories of the authentic leadership constructs. These constructs included relational transparency, internalized moral perspective, balanced information processing, and self-awareness. The original questionnaire had two versions (one rated by leaders and the other by followers), but because the present study only interviewed employees, ALQ's follower's survey was adopted. ${ }^{1}$

Following Walumbwa et al. (2008), we conducted a confirmatory factor analysis (CFA) and compared their fit using the AMOS maximum likelihood procedure to examine the validity of the higher-order authentic leadership construct. In the first model, all 16 items load onto the single authentic leadership factor (one-factor model). In the second model, the 16 items load onto the four factors when these factors are correlated with one another (first-order factor model). Finally, in the second model, all 16 items load on their respective factors, and the four first-order factors load on the second-order latent authentic leadership factor (second-order factor model). We employed various fit indices $\left(\chi^{2}, \chi^{2} / d f\right.$, CFI, and RMSEA) to assess the model fit. ${ }^{2}$

Table 2 shows the results of this analysis. The first- and second-order factor models provided a better fit to the data than the one-factor model. However, there was no significant $\chi^{2}$ difference between the first- and second-order factor models, which is inconsistent with the findings of Walumbwa et al. (2008), who employed US and Chinese samples and found a better fit for the second-order factor model than for the first-order factor model. Yet, Walumbwa et al. also suggested it is better to use a second-order factor model when tenable, thus we employed the second-order factor model for the analysis of the present study.

TABLE 2. COMPARISON OF ALQ FACTOR STRUCTURE

\begin{tabular}{lccccccc}
\hline \multicolumn{1}{c}{ Structure } & $\chi^{2}$ & $\mathrm{~d} / \mathrm{f}$ & $\chi^{2} / \mathrm{df}$ & $\Delta \chi_{\text {one }}^{2}$ & $\Delta \chi_{\text {first }}^{2}$ & CFI & RMSEA \\
\hline $\begin{array}{l}\text { One-factor model } \\
\text { (all 16 items) }\end{array}$ & 380.45 & 104 & 3.66 & & & .89 & .12 \\
$\begin{array}{l}\text { First-order factor } \\
\text { model }\end{array}$ & 255.78 & 98 & 2.61 & $124.67^{* * *}$ & & .94 & .09 \\
$\begin{array}{l}\text { Second-order factor } \\
\text { model }\end{array}$ & 260.53 & 100 & 2.61 & $119.92^{* * *}$ & 4.75 & .94 & .09 \\
\hline
\end{tabular}

NOTE: $N=193 ; \Delta \chi^{2}$ one indicates the $\chi^{2}$ difference between the one-factor model and the other two models; $\Delta \chi^{2}$ first indicates the $\chi^{2}$ difference between the first-order model and the second-order model; ${ }^{* * *} \mathrm{p}<.01$.

The standardized factor loadings for the second-order factor model ranged from .66 to .91 except for the fifth item whose loading is .50 ("My boss displays emotions that are consistent with his/her feelings"). In recent Korean leadership studies which employ ALQ, some items are often eliminated during CFA, including the aforementioned item (Kim and Jang 2012; You and Kim 2013; Han 2013). Interestingly, this does not seem to be the case in the studies of Walumbwa and his 
colleagues on the authentic leadership in Chinese firms (Walumbwa et al. 2008; 2010). How leadership styles in East Asian countries differ from one another has rarely been investigated in the academic research thus far. We do not further pursue this issue here for it is beyond the scope of this study, but it is indeed an important topic for future research.

Excluding this item, the internal reliability of the four first-order factors was as follows: relational transparency was .81; internalized moral perspective was .89 ; balanced processing was .86 ; and self-awareness was .89 .

\section{(3) Trust in Leaders}

For the present study, Podsakoff et al. (1990) trust measurement is employed. Of the original six items of this measure, we exclude an item asked in a negative manner ("I have a divided sense of loyalty toward my leader") from our final survey, as this type of question often confuses respondents. Our questionnaire includes a sample trust item, "I feel quite confident that my leader will always try to treat me fairly." The internal reliability of the measure was .92 .

\section{(4) Organizational Outcomes}

A selection of two organizational outcome measures follows Walumbwa et al. (2008). To measure organizational commitment, Mowday et al. (1979) developed a 15-item scale referred to as the Organizational Commitment Questionnaire (OCQ). Excluding some negative items to make the questionnaire more concise, we used an eight-item scale from OCQ. The newly constructed measure of organizational commitment includes a sample item, "I would accept almost any type of job assignment in order to keep working for this organization." The internal reliability was .84 .

The job performance measure combines items for an analysis of personal initiative, self-direction, and innovation from the three studies: four items for personal initiatives are borrowed from Bono and Judge (2003); four items for selfdirection from Stewart et al. (1996); and lastly four items for innovation from Welbourne et al. (1998). Unlike Walumbwa et al. who employed 10 out of the 12 items, we employ all 12 items to measure job performance (sample items include "I submit suggestions to improve work" for personal initiative; "I come up with new and original ideas for handling work" for self-direction; and "I come up with new ideas" for innovation). We conduct a CFA to examine whether the 12 items could properly measure a single factor. The results indicate a good model fit $\left(\chi^{2}=\right.$ 132.32, $d f=54, \chi^{2} / d f=2.45 ; \mathrm{CFI}=.93$; RMSEA $\left.=.09\right)$. In addition, an internal reliability was .92 , indicating that the combined scale is a reliable indicator of job performance. 


\section{RESULTS}

First, the discriminant validity of the two leadership constructs, ethical and authentic leadership, was examined. For this, we employed Fornell and Larcker's (1981) method, which compares the average variance extracted (AVE) of a factor of interest (in our case, authentic leadership) with the squared correlations between the chosen factor and the other factor (in our case, the factor to be compared was ethical leadership). If the AVE estimate exceeds the magnitude of the squared correlations, then it is considered that there is sufficient discriminant validity between the constructs. The AVE estimates for authentic leadership (.839) exceeded the squared correlation (.699), demonstrating a sufficient discriminant validity between ethical and authentic leadership.

We then tested Hypothesis 1, which posits that the two leadership variables are positively correlated to each other. According to the Pearson correlations in Table 3, the authentic leadership constructs show significant positive correlations with ethical leadership, providing initial support for this hypothesis. In addition, they were also significantly correlated with other key variables such as trust, organizational commitment and job performance.

\section{TABLE 3. MEAN, STANDARD DEVIATIONS AND CORRELATIONS}

\begin{tabular}{lccccccccc}
\hline & Mean & s.d. & 1 & 2 & 3 & 4 & 5 & 6 & 7 \\
\hline $\begin{array}{l}\text { 1. Ethical } \\
\text { leadership }\end{array}$ & 3.80 & .88 & 1 & & & & 1 & & \\
$\begin{array}{l}\text { 2. Relational } \\
\text { transparency }\end{array}$ & 2.60 & .89 & $.837^{* * *}$ & 1 & & & & \\
$\begin{array}{l}\text { 3. Internalized } \\
\text { moral perspective }\end{array}$ & 2.63 & .83 & $.806^{* * *}$ & $.805^{* * *}$ & 1 & & & \\
$\begin{array}{l}\text { 4. Balanced } \\
\text { processing }\end{array}$ & 2.67 & .87 & $.769^{* * *}$ & $.828^{* * *}$ & $.750^{* * *}$ & & & & \\
$\begin{array}{l}\text { 5. Self-awareness } \\
\text { 6. Trust }\end{array}$ & 2.59 & .86 & $.773^{* * *}$ & $.800^{* * *}$ & $.744^{* * *}$ & 1 & & & \\
7. Organization & 3.91 & .89 & $.878^{* * *}$ & $.815^{* * *}$ & $.797^{* * *}$ & $.748^{* * *}$ & 1 & & \\
$\quad$ commitment & 3.36 & .79 & $.440^{* * *}$ & $.391^{* * *}$ & $.424^{* * *}$ & $.375^{* * *}$ & $.392^{* * *}$ & 1 & \\
8. Job performance & 3.56 & .56 & $.454^{* * *}$ & $.428^{* * *}$ & $.456^{* * *}$ & $.328^{* * *}$ & $.358^{* * *}$ & $.482^{* * *}$ & 1 \\
\hline NOTE: $N=193{ }^{* * *} \mathrm{p}<.01$. & & & & & & & & \\
\hline
\end{tabular}

Figure 2 illustrates the result of the structural equation modelling analysis on a full mediation model. It turns out that the model provided a good fit to the data $\left(\chi^{2}=24.43, d f=18, \chi^{2} / d f=1.36\right.$; CFI $=.99$; RMSEA $\left.=.04\right)$. For the test of the mediation effect, we employed the bootstrapping method (Bollen and Stine 1990; Hayes 2013). The size of the bootstrapped sample is 1,000 (Cheung and Lau 2008) and a 95\% confidence interval was computed. Figure 1 shows the result, which provided support for Hypothesis 2, positing that ethical leadership positively 
affects trust in leaders $(\beta=.38, p=.011)$. The regression coefficient between authentic leadership and trust in leaders was also positive and statistically significant ( $\beta=.65, p=.003$ ), providing support for Hypothesis 3 which stated that authentic leadership positively affects trust in leaders. Next, as we examined the relationship between a mediating variable and outcome variables, trust in leaders shows significant positive effects on both organizational commitment $(\beta=.48, p=.003)$ and job performance $(\beta=.45, p=.002)$, providing support for Hypothesis 4 . Most importantly, the bootstrapped indirect effects are statistically significant between leadership and outcome variables. Through trust, authentic leadership affects organizational commitment $(\beta=.31, p=.001)$ and job performance $(\beta=.29, p$ $=.001$ ). Furthermore, mediated by trust, ethical leadership affects organizational commitment $(\beta=.19, p=.009)$ and job performance $(\beta=.17, p=.009)$.

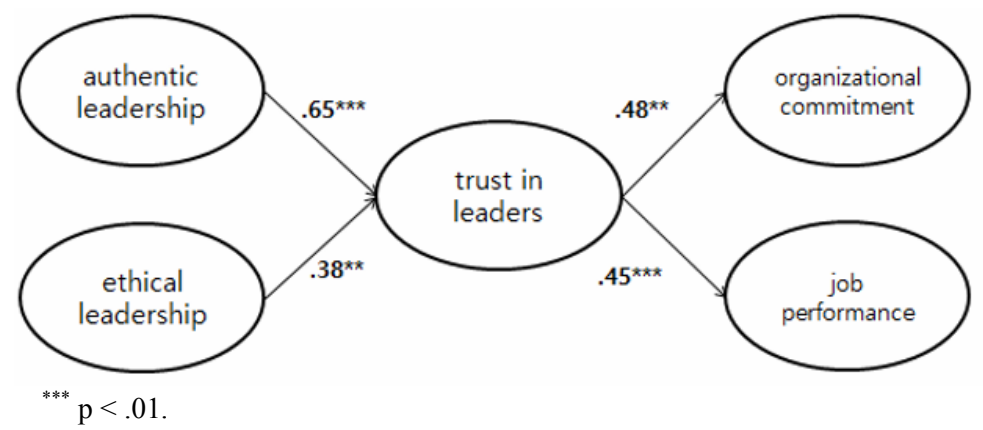

Figure 2. Results of Structural Equation Model with Full Mediation

Next, we tested an alternative model that included both direct and indirect paths from the two leadership variables to the two organizational outcomes. Results indicate that fit indices are in an acceptable range $\left(\chi^{2}=21.63, d f=14, \chi^{2} / d f=\right.$ 1.55; CFI $=.99$; RMSEA $=.05)$. However, in comparison with the full mediation model, there was no significant improvement in model fit $\left(\Delta \chi^{2}=2.8, \Delta d f=4, n s\right)$ therefore it can be concluded that the full mediation model is the best fitting model. We also employed the bootstrapping method as was in the analysis of the full mediation model, with results illustrated in Figure 3.

Figure 3 depicts that there is no direct effect of leadership on the two outcome variables. The alternative model shows some discrepancy from the full mediation model in that association between trust and job performances disappear, but the indirect effect of authentic leadership $(\beta=.22, p=.013)$ and ethical leadership ( $\beta$ $=.13, p=.016$ ) on organizational commitment is statistically significant. Additionally, we examine the direct impact of each leadership variable on the two outcome variables without a mediator. The results indicate that, with the control of ethical leadership, authentic leadership was not a significant predictor of the outcome 
variables. Furthermore, this was witnessed in vice versa; as we controlled the authentic leadership effect, ethical leadership did not appear to have a statistically significant effect on outcomes. Thus, the results provide support for Hypotheses 5 and 6.

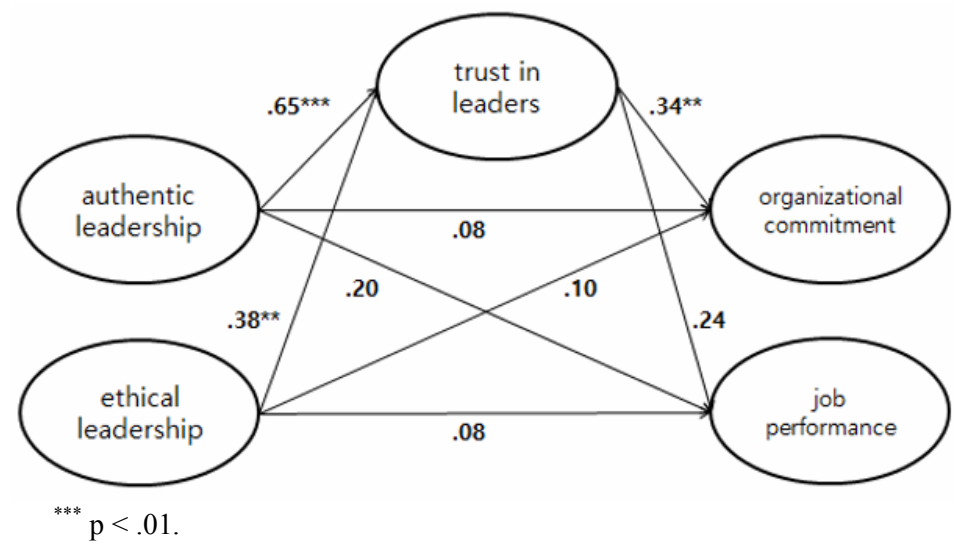

Figure 3. Results of the StRUCTURAL EQUATION MODEL With DiRECT AND INDIRECT EFFECTS

\section{DISCUSSION AND CONCLUSION}

Business leaders' ethical qualities have received widespread scholarly attention in recent years. Previous empirical studies discovered that ethical and/or authentic leadership styles have considerable influence on organizational outcomes. However, few empirical studies have explicated how these two leadership styles would work in a non-US context. The present study, which applies Walumbwa et al. (2008) theoretical and empirical model to a Korean context, indicates that the two leadership styles are only effective on organizational outcomes measured by organizational commitment and job performance when they are mediated by trust. In other words, we found that trust plays a pivotal role in leadership effectiveness due to the different way trust is formed in Korean firms than in western ones.

Furthermore, the results validated empirical measures of authentic and ethical leadership in a Korean context with the exclusion of a few culturally sensitive items (e.g., "My boss disciplines employees who violate ethical standards;" "My boss displays emotions that are consistent with his/her feelings;" "I am willing to put in a great deal of effort beyond that normally expected in order to help this organization be successful;" "I could just as well be working for a different organization as long as the type of work were similar;" "It would take very little change in my present circumstances to cause me to leave this organization;" "There's not much to be gained by sticking with this organization indefinitely; and 
"Often, I find it difficult to agree with this organization's policies on important matters relating to its employees").

Several theoretical and practical implications can be drawn from these results. Trust in leaders may be nurtured by leaders' authentic and ethical behavior. However, Korea has been known as a low-trust society by Fukuyama (1995), while its privately based trust among family members, school alumni and regional ties is relatively high. The concept of relational authenticity by Eagly (2005) can facilitate the understanding of the role of trust in the study of leadership in a Korean context. Eagly (2005) claimed that going beyond authenticity is required for the transmission of the leader's authenticity to followers. Authentic leaders should encourage their followers to identify with them in order to achieve successful outcomes. However, this identification is more challenging for female leaders than for male leaders, or for traditionally out-group members with little access to leadership roles. This suggests that ethical or authentic leadership behaviors are not sufficient for achieving organizational success unless leaders belong to majority groups within the organization in terms of blood, regional and school ties.

Furthermore, the results of the present study suggest that the workings of ethical or authentic leadership may be further clarified when cultural differences in trusting relationship are factored into the model. Kim et al. (2007) in their comparative study of conflict management styles in East Asian companies found that, when in conflict, Koreans prefer compromising with their supervisors more than the Chinese and Japanese. The authors suspected that Koreans may be more likely to emphasize mutual dependence between supervisors and subordinates than the other two groups. As Horak (2014) points out, Korean personal ties - Yongo, Yonjul, Inmaek - are much more complicated concepts than Chinese Guanxi, because they are not static, and sometimes one can develop into the other. Therefore, in future studies, how trust based upon personal ties is formed and functioned in Korean firms should be further investigated.

This study has a practical implication that a successful leadership environment may require more than a leaders' integrity and ethics. Cultural innovation within the business sector may be needed to ensure leadership behaviors that can bring about expected outcomes. Interestingly, in a recent lecture, a CEO stated that the major cause of his business success was the abolishment of personal networks and meetings based on school and regional ties, which guaranteed fairness and justice in human resource management. ${ }^{3}$ Korean conglomerates have been notorious for their exclusive family businesses and opaque management, but they are recently faced with the new challenges of becoming global companies. Korean civic organizations as well as the global community demand that large Korean companies adopt a more transparent and ethical management of corporations. Under this pressure, a number of companies had started adopting training programs raising ethical awareness and imposing ethical codes. Ethical practices, however, will not 
be sustainable unless they bring about productive outcomes.

The study has some limits, however, and to overcome these limitations, further research is required. First, although Harman's test allows the present study to adopt the results, using a single source for the survey may still raise a concern about CMV; therefore, future studies need to overcome this source of bias. Second, now that the study presented in this paper provides insight into the importance of trust to improve the effects of ethical/authentic leadership in Korean firms by providing personal intimacy, the multidimensionality of trust should be taken into consideration in future studies. In this regard, McAllister's (1995) cognitive and affective trust model could be useful. Finally, there should be more in-depth investigations on ethical/authentic leadership in firms in East Asian countries. Vibrant economies in the region share some cultural traits but diverge on many fronts (Stedham et al. 2008); nevertheless, little is known from the comparative perspective about how values in leadership affect leader-employee relationship and organizational performances in these countries. Obtaining this knowledge would benefit both cross-cultural leadership studies and regional business practices.

\section{REFERENCES}

Akker, L., L. Heres, K. Lasthuizen, and F. Six. 2009. Ethical Leadership and Trust: It's All About Meeting Expectations. International Journal of Leadership Studies 5(2): 102-122.

Avey, J. B., M. E. Palanski, and F. O. Walumbwa. 2010. When Leadership Goes Unnoticed: The Moderating Role of Follower Self-esteem on the Relationship between Ethical Leadership and Follower Behavior. Journal of Business Ethics 98(4): 573-582.

Avolio, B. J., W. L. Gardner, F. O. Walumbwa, F. Luthans, and D. R. May. 2004. Unlocking the Mask: A Look at the Process by Which Authentic Leaders Impact Follower Attitudes and Behaviors. Leadership Quarterly 15: 801-823.

Avolio, B. J. and W. L. Gardner. 2005. Authentic Leadership Development: Getting to the Root of Positive Forms of Leadership. Leadership Quarterly 16: 315338.

Bass, B. M. 1990. Bass and Stogdill's Handbook of Leadership (3rd ed.). New York: Free Press.

Berkowitz, D. and J. H. Lee. 2004. Media Relations in Korea: Cheong between Journalist and Public Relations Practitioners. Public Relations Review 30: 431-437.

Bollen, K. A. and R. Stine. 1990. Direct and Indirect Effects: Classical and Bootstrap Estimates of Variability. Sociological Methodology 20: 115-140.

Bono, J. E. and T. A. Judge. 2003. Self-concordance at Work: Toward Understanding the Motivational Effects of Transformational Leaders. Academy of Management 
Journal 46: 554-571.

Brown, M. E., L. K. Trevino, and D. A. Harrison. 2005. Ethical Leadership: A Social Learning Perspective for Construct Development and Testing. Organizational Behavior and Human Decision Processes 97: 117-134.

Brown, M. E. and L. K. Trevino. 2006. Ethical Leadership: A Review and Future Directions. Leadership Quarterly 17: 595-616.

Burk, C. S., D. E. Sims, E. H. Lazzara, and E. Salas. 2007. Trust in Leadership: A Multi-level Review and Integration. The Leadership Quarterly 18: 606-632.

Caldwell, C., L. A. Hayes, R. Karri, and P. Bemal. 2008. Ethical Stewardship Implications for Leadership and Trust. Journal of Business Ethics 78: 153164.

Cheung, G. W. and R. S. Lau. 2008. Testing Mediation and Suppression Effects of Latent Variables: Bootstrapping with Structural Equation Models. Organizational Research Methods 11(2): 296-325.

Cho, Y. H., G. C. Yu, M. K. Joo, and C. Rowley. 2014. Changing Corporate Culture over Time in South Korea. Asia Pacific Business Review 20(1): 9-17.

Chungtai, A., M. Byrne, and B. Flood. 2014. Linking Ethical Leadership to Employee Well Being: The Role of Trust in Supervisor. Journal of Business Ethics 128(3): 653-663.

Clapp-Smith, R., G. R. Vogelgesang, and J. B. Avey. 2009. Authentic Leadership and Positive Psychological Capital: The Mediating Role of Trust at the Group Level of Analysis. Organizational Studies 15(3): 227-240.

Dirks, K. T. and D. L. Ferrin. 2002. Trust in Leadership: Meta-analytic Findings and Implications for Research and Practice. Journal of Applied Psychology 87: 611-628.

Eagly, A. H. 2005. Achieving Relational Authenticity in Leadership: Does Gender Matter?. The Leadership Quarterly 16: 459-474.

Enderle, G. 1982. Some Perspectives of Managerial Ethical Leadership. Journal of Business Ethics 6(8): 657-663.

Fornell, C. and D. Larcker. 1981. Structural Equation Models with Unobservable Variables and Measurement Error. Journal of Marketing Research 18(1): 3950 .

Fukuyama, F. 1995. Trust: The Social Virtues and the Creation of Prosperity. New York: Free Press.

Gardner, W. L., B. J. Avolio, F. Luthans, D. R. May, and F. O. Walumbwa. 2005. Can You See the Real Me?. A Self Based Model of Authentic Leader and Follower Development. Leadership Quarterly 16: 343-372.

Gardner, W. L., B. J. Avolio, and F. O. Walumbwa. (Eds.). 2006. Authentic Leadership Theory and Practice: Origins, Effects and Development. Oxford, UK: Elsevier Science.

Gronn, P. 2001. Crossing the Great Divides: Problems of Cultural Diffusion for 
Leadership in Education. International Journal of Leadership in Education: Theory and Practice 4(4): 401-414.

Han, B. J. 2013. A Study on the Effects of Transformational and Authentic Leadership on Organizational Commitment: Focused on the Mediating Effects of Psychological Capital and LMX. Hankuk Jojik Hakheobo (Korean Journal of Organizational Studies) 10(1): 157-201.

Han, Y., Z. Peng, and Y. Zhu. 2012. Supervisor-Subordinate Guanxi and Trust in Supervisor: A Qualitative Inquiry in the People's Republic of China. Journal of Business Ethics 108: 313-324.

Harman, D. 1967. A Single Factor Test of Common Method Variance. Journal of Psychology 35: 359-378.

Harvey, P., M. J. Martinko, and W. L. Gardner. 2006. Promoting Authentic Behavior in Organizations: An Attributional Perspective. Journal of Leadership Organizational Studies 12(3): 1-11.

Hayes, A. 2013. Introduction to Mediation, Moderation, and Conditional Process Analysis: A Regression-based Approach. New York and London: The Guilford Press.

Horak, S. 2014. Antecedents and Characteristics of Informal Relation-based Networks in Korea: Yongo, Yonjul, and Inmaek. Asia Pacific Business Review 20(1): 78-108.

Jo, S. S. and Y. W. Kim. 2004. Media or Personal Relations? Exploring Media Relations Dimensions in South Korea. Journalism and Mass Communication Quarterly 81(2): 292-306.

Kim, T. Y., C. Wang, M. Kondo, and T. H. Kim. 2007. Conflict Management Styles: The Differences among the Chinese, Japanese and Koreans. International Journal of Conflict Management 18(1): 23-41.

Kim, H. S. and B. G. Chung. 2008. Mediating Effect of Trust on the Relationship between Ethical Leadership and Organizational Effectiveness. Kyung-young Kyung-je Yeonku (Journal of Management and Economic Research) 30(2): 29-54.

Kim, M. S. and C. S. Jang. 2012. The Effects of Authentic Leadership on Employee Positive Psychological Capital and Affective Commitment. Injeok Jawon Kaebalyeonku (Journal of Human Resource Development Research) 15(1): 101-125.

May, D. R., A. Chan, T. Hodges, and B. J. Avolio. 2003. Developing the Moral Component of Authentic Leadership. Organizational Dynamics 32: 247-260.

Mayer, D. M., M. Kuenzi, R. L. Greenbaum, M. Bardes, and R. B. Salvador. 2009. How Low Does Ethical Leadership Flow? Test of a Trickle-down Model. Organizational Behavior and Human Processes 108: 1-13.

Mayer, D. M., K. Aquino, R. L. Greenbaum, and M. Kuenzi. 2012. Who Displays Ethical Leadership, and Why Does It Matter? An Examination of Antecedents 
and Consequences of Ethical Leadership. Academy of Management Journal 55(1): 151-171.

McAllister, D. J. 1995. Affect- and Cognition-based Trust as Foundations for Interpersonal Cooperation in Organizations. Academy of Management Journal 38: 24-59.

Mowday, R. T., R. M. Steers, and L. W. Porter. 1979. The Measurement of Organizational Commitment. Journal of Vocational Behavior 14: 224-247.

Palanski, M. E. and F. J. Yammarino. 2007. Integrity and Leadership: Clearing the Conceptual Confusion. European Management Journal 25: 171-184.

Pillai, R., C. A. Schriesheim, and E. S. Williams. 1999. Fairness Perceptions and Trust as Mediators for Transformational and Transactional Leadership: A Two-sample Study. Journal of Management 25(6): 897-933.

Podsakoff, P. M., S. Moorman, and R. Fetter. 1990. Transformational Leader Behaviors and Their Effects on Followers' Trust in Leader, Satisfaction, and Organizational Citizenship Behaviors. Leadership Quarterly 1: 107-142.

Podsakoff, P. M., S. C. MacKenzie, N. P. Podsakoff, and J. Lee. 2003. Common Method Biases in Behavioral Research: A Critical Review of the Literature and Recommended Remedies. Journal of Applied Psychology 88: 879-903.

Ponnu, C. and G. Tennakoon. 2009. The Association Between Ethical Leadership and Employee Outcomes-the Malaysian Case. Electronic Journal of Business Ethics and Organization Studies 14(1): 21-32.

Qi, Y. and L. Ming-xia. 2014. Ethical Leadership, Organizational Identification and Employee Voice: Examining Moderated Mediation Process in the Chinese Insurance Industry. Asia Pacific Business Review 20(2): 231-248.

Ruiz-Palomino, P., C. Ruiz-Amaya, and H. Knörr. 2011. Employee Organizational Citizenship Behavior: The Direct and Indirect Impact of Ethical Leadership. Canadian Journal of Administrative Sciences 28: 244-258.

Rotter, J. B. 1967. A New Scale for the Measurement of Interpersonal Trust. Journal of Personality 35(4): 651-665.

Shin, Y. 2012. CEO Ethical Leadership, Ethical Climate, Climate Strength, and Collective Organizational Citizenship Behavior. Journal of Business Ethics 108: 299-312.

Shin, Y., S. Y. Sung, J. N. Choi, and M. S. Kim. 2014. Top Management Ethical Leadership and Firm Performance: Mediating Role of Ethical and Procedural Justice Climate. Journal of Business Ethics.

Stedham, Y., J. H. Yamamura, and S. C. Lai. 2008. Business Ethics in Japan and Taiwan: Relativist and Utilitarian Perspectives. Asia Pacific Business Review 14(4): 535-551.

Stewart, G. L., K. P. Carson, and R. L. Cardy. 1996. The Joint Effects of Conscientiousness and Self-leadership Training on Employee Self-directed Behavior in a Service Setting. Personnel Psychology 49: 143-164. 
Trevino, L. K., M. Brown, and L. P. Hartman. 2000. Moral Person and Moral Manager: How Executives Develop a Reputation for Ethical Leadership. California Management Review 42(4): 128-142.

Walumbwa, F., B. J. Avolio, W. Gardner, T. Wernsing, and S. Peterson. 2008. Authentic Leadership: Development and Validation of a Theory-based Measure. Journal of Management 34(1): 89-126.

Walumbwa, F., P. Wang, H. Wang, J. Schaubroeck, and B. J. Avolio. 2010. Psychological Processes Linking Authentic Leadership to Follower Behaviors. The Leadership Quarterly 21: 901-914.

Welbourne, T. M., D. E. Johnson, and A. Erez. 1998. The Role-based Performance Scale: Validity Analysis of a Theory Based Measure. Academy of Management Journal 41: 540-555.

Wong, C. A. and G. G. Cummings. 2009. The Influence of Authentic Leadership Behaviors on Trust and Work Outcomes of Health Care Staff. Journal of Leadership Studies 3(2): 6-23.

You, J. H. and T. K. Kim. 2013. Authentic Leadership and Self-efficacy Have an Effect on the Organizational Effectiveness. Nodong Yeonku (Journal of Labor Studies) 25: 219-256.

Yum, Y. O. and D. J. Canary. 2003. Maintaining Relationship in Korea and the United States: Features of Korean Culture that Affect Relational Maintenance Beliefs and Behaviors. In D. J. Canary and M. Dainton (Eds.), Maintaining Relationships through Communication: 277-289. NJ: Erlbaum Associates.

Zang, H., A. M. Everett, G. Elkin, and M. H. Cone. 2012. Authentic Leadership Theory Development: Theorizing on Chinese Philosophy. Asia Pacific Business Review 18(4): 587-605.

Zhu, W., D. R. May, and B. J. Avolio. 2004. The Impact of Ethical Leadership Behavior on Employee Outcomes: The Roles of Psychological Empowerment and Authenticity. Journal of Leadership and Organizational Studies 11(1): 16-26. 


\section{ENDNOTES}

1 We translated the questionnaire into Korean and then back-translated it into English to obtain permission to use the instrument from the publisher, Mind Garden, Inc. (www.mindgarden.com).

2 For $\chi^{2} / d f$, a ratio less than 2.00 is interpreted as a good fit, and a CFI value greater than equal to 0.90 (close to 1) and an RMSEA value less than or equal to 0.05 are considered to be a good fit.

3 President Yun Suk-keum of Woongjin Group in Celebrity Lecture, organized by Hunet. January 19, 2012. 